\title{
A study of the effect of dietary fiber fractions obtained from artichoke (Cynara cardunculus L. var. scolymus) on the growth of intestinal bacteria associated with health
}

\author{
Eliana N. Fissore, a,b Cinthia Santo Domingo, ${ }^{a, b}$ Lía N. Gerschenson ${ }^{a, b}$ and \\ Leda Giannuzzi๋ ${ }^{b, c}$
}

\begin{abstract}
The effect of different fractions enriched in soluble fiber obtained from artichoke using citric acid or citric acid/hemicellulase on the selective growth of Lactobacillus plantarum 8114 and Bifidobacterium bifidum ATCC 11863 was evaluated. Gompertz modeling of Lactobacillus plantarum 8114 growth showed a higher specific growth rate $\left(\mu: 0.16 \mathrm{~h}^{-1}\right)$ in the presence of fractions isolated from stems using hemicellulase (fraction A) than in the presence of glucose $\left(\mu: 0.09 \mathrm{~h}^{-1}\right)$. In the case of Bifidobacterium bifidum 11863, the highest $\mu$ was obtained for the microorganism grown in the presence of fraction $\mathrm{A}$ and for the fraction isolated from stems without hemicellulase, their rate being twice that observed for glucose $\left(0.04 \mathrm{~h}^{-1}\right)$. The positive prebiotic activity scores observed with respect to Escherichia coli 25922 indicated that fibers assayed are metabolized as well as glucose by Lactobacillus plantarum 8114 and Bifidobacterium bifidum ATCC 11863 and that they are selectively metabolized by these microorganisms. The potential capacity to selectively stimulate the growth of intestinal bacteria associated with health shown by fraction A can be ascribed to its high inulin and low methylation degree pectin contents.
\end{abstract}

Received 23rd January 2015, Accepted 9th April 2015

DOI: $10.1039 / c 5 f o 00088 b$

www.rsc.org/foodfunction
Roberfroid $^{4}$ stated that the classification of a food ingredient as a prebiotic requires a scientific demonstration that the ingredient:

(1) resists gastric acidity, hydrolysis by mammalian enzymes and gastrointestinal absorption;

(2) is fermented by the intestinal microflora;

(3) stimulates selectively the growth and/or activity of intestinal bacteria associated with health and wellbeing.

As the field of prebiotics has developed, so has the methodology for investigating functionality. In general, the changes of flora in response to diet have been studied using strains of Bifidobacterium spp. and Lactobacillus spp. and comparing its growth with the one of other bacteria such as Bacteroides spp., Clostridium spp., Eubacterium spp. and Escherichia coli. ${ }^{5}$ The number of strains tested varies with different reports. Currently, it is proposed to evaluate the fulfillment of the three requirements previously mentioned for defining a food ingredient as a prebiotic, with the selective stimulation of growth being the first stage in the evaluation of the characteristics of different food ingredients. ${ }^{3}$ For example, Marotti et al. ${ }^{6}$ studied the prebiotic effect of soluble fibers from seven modern, two old and one ancient durum-type wheat varieties on Lactobacillus and Bifidobacterium strains. In that study, the behaviors of L. plantarum L12 and B. pseudocatenulatum B7003 were studied in the presence of wheat fiber and glucose and 
compared with the behavior of Escherichia coli ATCC 25645 and Klebsiella pneumoniae GC 23a in the presence of both carbon sources to evaluate the prebiotic activity of wheat fiber. Fiber microbial utilization was highly variable and dependent on the strain. Soluble dietary fibers from durum-type wheat grains were identified as a potential prebiotic substrate for the selective proliferation of B. pseudocatenulatum B7003 and L. plantarum L12 in vitro. Several studies have shown that the ability of lactobacilli and bifidobacteria to ferment prebiotic carbohydrates is both strain and substrate specific. ${ }^{7,8}$ In addition, it is not clear which prebiotic carbohydrates are the most suitable substrates for the selective growth of specific strains. Recently, several quantitative approaches were devised to determine the functional activity of prebiotics during in vitro fermentation conditions. In general, these studies provided indices that reflect the relative ability of a given prebiotic to produce specific effects, and are based on the measurement of microbial populations, growth rates, substrate assimilation, and/or short-chain fatty acid production. The indices were then used to rank various carbohydrates according to their potential to stimulate the growth of specific members of a mixed microflora. However, as fermentation of prebiotics is dependent on the bacterial strain, rather than being based on the species or genera, it is important to understand the extent to which the metabolism of prebiotics occurs by specific strains of bacteria, especially for those organisms whose

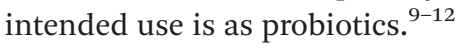

In a previous work, Fissore et al. ${ }^{13}$ reported the antioxidant and in vitro antiviral effects of dietary fiber fractions isolated with citric acid or citric acid/hemicellulase from the bracts, stems and hearts of artichoke (Cynara cardunculus L. var. scolymus). These fractions contained inulin and pectin. The aim of the present study is to quantify the extent to which those fractions selectively stimulate the growth of the strains Lactobacillus plantarum 8114 and Bifidobacterium bifidum ATCC 11863 with the purpose of helping in the understanding of the potential of different fibers to act as prebiotic substrates. In addition, the kinetic parameters of microbial growth were also studied.

\section{Materials and methods}

\subsection{Sample preparation}

Artichokes (Cynara cardunculus L. var. scolymus) harvested in Argentina were bought in the local market. Bracts, hearts and stems were separated, washed with distilled water, dried $\left(85{ }^{\circ} \mathrm{C}, 2.5 \mathrm{~h}\right)$ in a convection oven $\left(0.508 \mathrm{~m} \mathrm{~s}^{-1}\right.$ of air rate), milled (E909, Wemir, Buenos Aires, Argentina) and sieved to obtain powders enriched with cell wall material (CWM), with particle sizes in the range $420-710 \mu \mathrm{m}$.

Each CWM was treated as follows:

$10 \mathrm{~g}$ of CWM was poured into a beaker containing $1000 \mathrm{~mL}$ of $0.05 \mathrm{~mol} \mathrm{~L}^{-1}$-sodium citrate buffer solution ( $\mathrm{pH} 5.2$ ) with $0.01 \mathrm{~g}$ per $100 \mathrm{~g}$ of sodium azide (final concentration). Each system was heated for $5 \mathrm{~min}$ at $70^{\circ} \mathrm{C}$, under stirring, cooled to
Table 1 Different fractions obtained from the treatment of artichoke cell wall material (CWM)

\begin{tabular}{lll}
\hline Fraction & $\begin{array}{l}\text { CWM from } \\
\text { artichoke }\end{array}$ & $\begin{array}{l}\text { Treatment with } \\
\text { hemicellulase }\end{array}$ \\
\hline A & Stem & + \\
B & Stem & - \\
C & Bracts & + \\
D & Bracts & - \\
E & Heart & + \\
F & Heart & -
\end{tabular}

$30{ }^{\circ} \mathrm{C}$ and then maintained under constant stirring for $20 \mathrm{~h}$ either without or with addition of $0.25 \mathrm{~g}$ of hemicellulase. Deionized (Milli-Q ${ }^{\mathrm{TM}}$, USA) water was used for all treatments. Insolubles obtained after digestion were separated through filtration under vacuum with a glass fiber filter (Schleicher \& Schuell, Dassel, Germany), and cell wall polysaccharides were finally precipitated from each supernatant through ethanol (96\%, v/v) addition ( 2 volumes). The precipitate was collected through filtration under vacuum using a glass fiber filter, washed and, finally, freeze-dried.

The fractions obtained are summarized in Table 1.

\subsection{Bacterial strains}

Lactobacillus plantarum 8114 (American Type Culture Collection, Rockville, MD, USA), Bifidobacterium bifidum ATCC 11863 (MEDICA-TEC, Buenos Aires, Argentina) and Escherichia coli 25922 (American Type Culture Collection, Rockville, MD, USA) were used for this study.

The specific test strains of L. plantarum 8114 and B. bifidum 11863 were selected because they were either already established as probiotics or they have potential probiotic properties.

All the microorganism cultures were maintained at $-80{ }^{\circ} \mathrm{C}$. In the case of Lactobacillus plantarum MRS Broth (Difco Laboratories, Sparks, MD, USA) containing 15\% (w/v) glycerol was used while Tryptic Soy Broth (TSB; Difco Laboratories) containing $15 \%(\mathrm{w} / \mathrm{v})$ glycerol was used for $E$. coli and MRS broth (Difco Laboratories, Sparks, MD, USA) supplemented with $0.05 \%$ L-cysteine $\mathrm{HCl}$ (decrease of oxidation-reduction potential) was used for Bifidobacterium bifidum.

\subsection{Prebiotic activity}

As mentioned before, according to Roberfroid ${ }^{4}$ one of the requirements for the classification of a food ingredient as a prebiotic is the scientific demonstration that it stimulates selectively the growth and/or activity of intestinal bacteria associated with health and wellbeing. This means that the prebiotic activity reflects the ability of a given substrate to support the growth of an organism relative to other organisms and relative to growth on a non-prebiotic substrate, such as glucose.

2.3.1. Prebiotic activity score. Huebner et al. ${ }^{14}$ established a quantitative score to describe the extent to which prebiotics 
support the selective growth of lactobacilli and bifidobacteria. This score is calculated as:
For prebiotic activity studies, frozen cultures were streaked onto MRS agar for L. plantarum 8114, onto MRS agar sup-

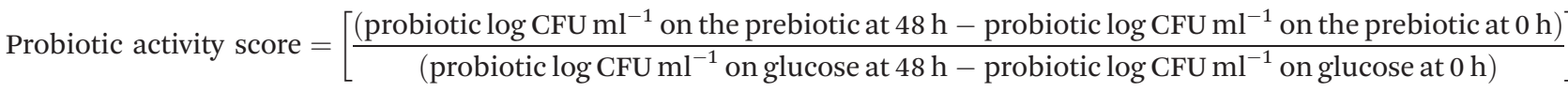

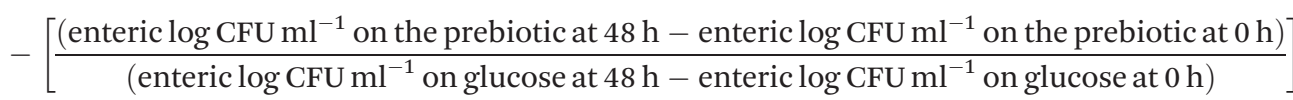

where CFU means colony forming units.

Carbohydrates have a positive prebiotic activity score if they are metabolized as well as glucose by probiotic strains and are selectively metabolized by probiotics but not by other intestinal bacteria.

2.3.2. Prebiotic activity score assay. The procedure used is described in Fig. 1. plemented with $0.05 \%$ L-cysteine $\mathrm{HCl}$ for B. bifidum 11863 and onto tryptic soy agar (TSA) for E. coli ATCC 25922. Then, E. coli was incubated at $37^{\circ} \mathrm{C}$ for $24-48 \mathrm{~h}$ under aerobic conditions, Lactobacillus plantarum and B. bifidum were incubated at $37^{\circ} \mathrm{C}$ for 24-48 $\mathrm{h}$ in an anaerobic chamber (Oxoid, Cambridge, UK) under anaerobic atmosphere (Anaerocult A, Merck, Darmstadt, Germany). After that, one colony from each plate was trans-

\section{FROZEN CULTURES}

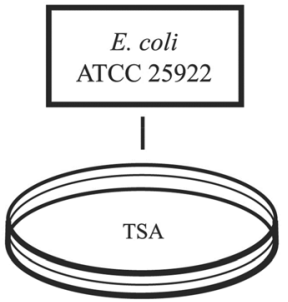

AEROBIC

Incubation $37^{\circ} \mathrm{C} 24-48 \mathrm{hs}$

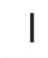

TS Broth

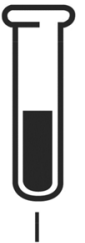

AEROBIC Incubation $37^{\circ} \mathrm{C} 48 \mathrm{hs}$

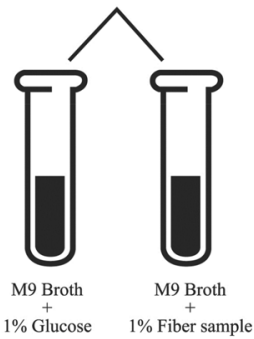

+
$1 \%$ Glucose
$1 \%$ Fiber sample

AEROBIC Incubation

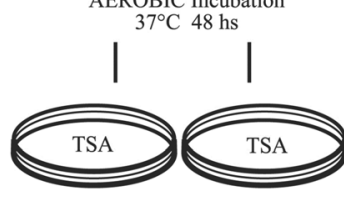

AEROBIC Incubation

$37^{\circ} \mathrm{C} 48 \mathrm{hs}$

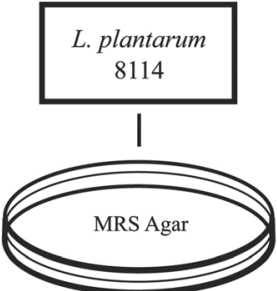

ANAEROBIC

Incubation $37^{\circ} \mathrm{C}$ 24-48 hs

MRS Broth

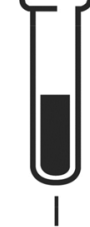

ANAEROBIC Incubation $37^{\circ} \mathrm{C} 48 \mathrm{hs}$

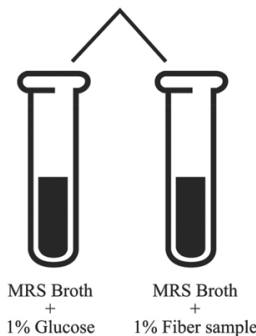

$\begin{array}{cc}+ & + \\ 1 \% \text { Glucose } & + \\ & \end{array}$

ANAEROBIC Incubation

$37^{\circ} \mathrm{C} 48 \mathrm{hs}$

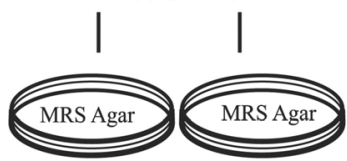

ANAEROBIC Incubation $37^{\circ} \mathrm{C} 48 \mathrm{hs}$

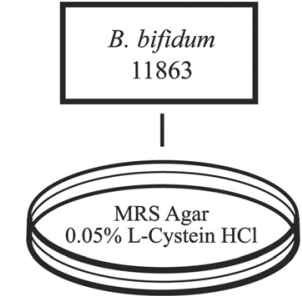

ANAEROBIC

Incubation $37^{\circ} \mathrm{C} 24-48 \mathrm{hs}$

I

MRS Broth $+0.05 \%$ L-Cystein HCl

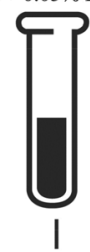

ANAEROBIC

Incubation $37^{\circ} \mathrm{C} 48 \mathrm{hs}$

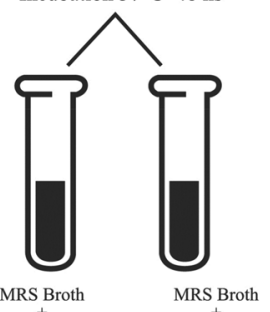

$0.05 \%$ L-Cystein $\mathrm{HCl} \quad 0.05 \%$ L-Cystein $\mathrm{HCl}$

$1 \%$ Glucose $1 \%$ Fiber sample

ANAEROBIC Incubation

$37^{\circ} \mathrm{C} 48$ hs

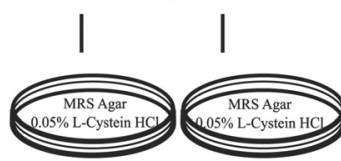

ANAEROBIC Incubation $37^{\circ} \mathrm{C} 48 \mathrm{hs}$

Fig. 1 Flow-graph of method used for prebiotic activity score assay. 
ferred into $10 \mathrm{ml}$ of MRS broth for L. plantarum or into $10 \mathrm{ml}$ of MRS broth supplemented with $0.05 \%$ L-cysteine $\mathrm{HCl}$ for $B$. bifidum and were incubated overnight under anaerobic conditions. For E. coli, one colony from a TSA plate was inoculated into $10 \mathrm{ml}$ of tryptic soy broth (TSB) and incubated under aerobic conditions for $48 \mathrm{~h}$.

The assay was performed by adding $1 \%(\mathrm{v} / \mathrm{v})$ of an overnight culture of $L$. plantarum to separate tubes containing MRS broth with $1 \%(\mathrm{w} / \mathrm{v})$ glucose or $1 \%(\mathrm{w} / \mathrm{v})$ fiber samples. The culture of B. bifidum $(1 \%(\mathrm{v} / \mathrm{v}))$, was added to separate tubes containing MRS broth supplement with $0.05 \%$ L-cysteine $\mathrm{HCl}$ and $1 \%(\mathrm{w} / \mathrm{v})$ glucose or $1 \%(\mathrm{w} / \mathrm{v})$ fiber samples. In both cases, cultures were incubated at $37{ }^{\circ} \mathrm{C}$ for $48 \mathrm{~h}$ under anaerobic atmosphere generation system (Anaerocult A, Merck, Darmstadt, Germany) in an anaerobic chamber (Oxoid, Cambridge, UK). At 0 and $48 \mathrm{~h}$ of incubation, samples were enumerated in triplicate using the serial dilution method on MRS agar (L. plantarum) or MRS agar supplemented with $0.05 \%$ L-cysteine $\mathrm{HCl}$ (B. bifidum) with incubation at $37{ }^{\circ} \mathrm{C}$ under anaerobic conditions and the results were calculated as $\mathrm{CFU}$ $\mathrm{mL}^{-1}$ of culture.

E. coli culture ATCC 25922 (1\%, v/v) was added to separate tubes containing M9 Minimal Medium broth ${ }^{15}$ with $1 \%(\mathrm{w} / \mathrm{v})$ glucose or $1 \%(\mathrm{w} / \mathrm{v})$ fiber samples and incubated at $37{ }^{\circ} \mathrm{C}$ for $48 \mathrm{~h}$ under aerobic conditions as described by Huebner et al. ${ }^{14,16}$ and Marotti et al. ${ }^{6}$ At 0 and $48 \mathrm{~h}$ of incubation, inoculated samples were enumerated in duplicate on TSA plates with incubation at $37^{\circ} \mathrm{C}$ under aerobic conditions. The results were expressed as CFU mL $\mathrm{mL}^{-1}$ of culture.

Each assay was replicated a minimum of three times.

\subsection{Modelling of the microbial growth}

Cell counts were evaluated by plating in triplicate after 12, 24, 36,48 and $60 \mathrm{~h}$ of fermentation at $37^{\circ} \mathrm{C}$. Samples $(1.0 \mathrm{~mL})$ were added to $9.0 \mathrm{~mL}$ of $0.1 \mathrm{~g}$ per $100 \mathrm{~g}$ sterile peptonated water; then, appropriate dilutions were made. Subsequently, L. plantarum 8114 was plated into MRS Agar and incubated under anaerobic conditions at $37^{\circ} \mathrm{C}$. B. bifidum 11863 was counted in MRS Agar supplemented with 0.05\% L-cysteine $\mathrm{HCl}$ with incubation at $37{ }^{\circ} \mathrm{C}$ under anaerobic conditions. Incubation was performed for $60 \mathrm{~h}$.

L. plantarum and B. bifidum counts were mathematically modeled for better understanding the behavior of the cultures in the presence of the different fractions of interest. The Gompertz model was used, which is one of the most recommended models ${ }^{17,18}$ and is expressed through the following equation:

$$
\log N=a+c \exp (-\exp (-b)(t-m))
$$

where $\log N$ is the decimal logarithm of microbial counts (log (CFU mL $\left.\mathrm{m}^{-1}\right)$ ) at time $t$; $a$ is the asymptotic log count as time decreases indefinitely, which is approximately equivalent to the log of the initial level of bacteria $\left(\log \left(\mathrm{CFU} \mathrm{mL}{ }^{-1}\right)\right)$; $c$ is the $\log$ count increment or number of $\log$ cycles of growth as time increases indefinitely $\left(\log \left(\mathrm{CFU} \mathrm{mL}^{-1}\right)\right) ; b$ is the relative maximum growth rate at time $m\left(\mathrm{~h}^{-1}\right) ; m$ is the time required to reach the maximum growth rate $\left(\mathrm{h}^{-1}\right)$. Using these parameters, the specific growth rate $\mu=b c / e\left(\mathrm{~h}^{-1}\right)$, with $e=2.7183$ ( $\log \left(\mathrm{CFU} \mathrm{mL}^{-1}\right.$ per day)), lag phase duration (LPD $\left.=m-(1 / b)\right)$ (h) and the maximum population density, MPD $=a+c(\log$ (CFU $\left.\mathrm{mL}^{-1}\right)$ ) can be evaluated.

\subsection{Statistical analysis}

Results of experiments are presented as mean \pm standard deviation of three independent determinations. One-way analysis of variance (ANOVA) followed by Duncan's new multiple range tests were used to compare the mean values $(\alpha: 0.05)$.

All statistical analyses were performed with SYSTAT INC, version 12.0 (Systat Software Inc., San Jose, CA).

\section{Results and discussion}

Fissore et $a .^{13}$ stated that the fractions enriched in soluble fiber studied in the present research are constituted by 72.0-96.8 $\mathrm{g}$ per $100 \mathrm{~g}$ of carbohydrates, $1.8-9.2 \mathrm{~g}$ per $100 \mathrm{~g}$ of proteins and contain phenolic compounds (2.1-8.2 g per $100 \mathrm{~g})$. Carbohydrates comprise uronic acids (14.0-18.2 g per $100 \mathrm{~g})$, neutral sugars $(0.8-44.3 \%)$ of pectins, and inulin (38.0-55.0\%). The highest inulin contents were observed for all fractions isolated in the absence of enzymatic treatment (fractions B, D and F). The lowest degree of methylation of pectin was observed for the fraction isolated from the stem in the presence of hemicellulase (fraction A). The lowest protein and phenol contents were observed for fractions isolated from bracts (fractions C and D) (Table 2).

\subsection{Kinetic behavior of the Lactobacillus plantarum 8114 and Bifidobacterium bifidum 11863 growth in different fibers}

When studying the substrate requirements and specificities of individual bifidobacterial and Lactobacillus strains, two factors are especially important. The first is the rate at which an organism can grow on a particular carbon source, as this will influence its ability to compete with other bacteria in the colon. ${ }^{19}$ The other is the extent to which the substrate is converted into bacterial mass, because cell numbers will affect the degree of pre- or probiotic activity. For this reason, it is important to study the kinetic behavior of the probiotic bacteria Lactobacillus plantarum 8114 and Bifidobacterium bifidum 11863 in the different substrates.

Fig. 2 shows Lactobacillus plantarum 8114 (Panel a) and Bifidobacterium bifidum 11863 (Panel b) growth on the different fractions of dietary fiber during incubation at $37{ }^{\circ} \mathrm{C}$ for a maximum period of $60 \mathrm{~h}$. Full lines represent the mathematical modeling of data to the Gompertz equation. As can be observed, a good agreement was achieved between the model and the experimental data; the parameters obtained are shown in Table 3.

In the case of Lactobacillus plantarum 8114 strains, the highest specific growth rate $\left(\mu: 0.16 \mathrm{~h}^{-1}\right)$ was observed for fraction A, indicating that a high rate of cell proliferation occurred on this carbon source within a short period of incubation 
Table 2 Chemical composition of the fractions enriched in soluble fibers and isolated from bracts, hearts and stems of artichoke ${ }^{a}$

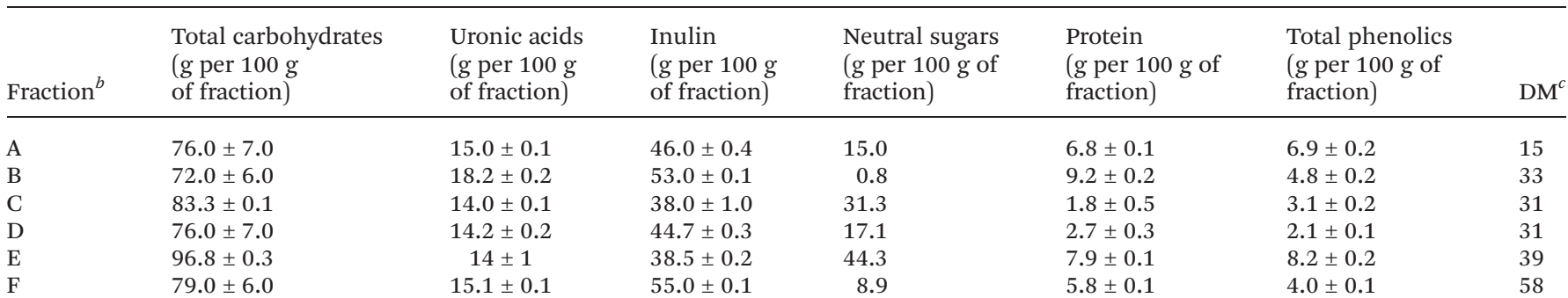

${ }^{a}$ Fissore et al. (2014). ${ }^{13}{ }^{b}$ A: fraction obtained form artichoke stem CWM with hemicellulase. B: fraction obtained form artichoke stem CWM with no enzyme addition. C: fraction obtained from artichoke bracts CWM with hemicellulase. D: fraction obtained from artichoke bracts CWM with no enzyme addition. E: fraction obtained from artichoke heart CWM with hemicellulase. F: fraction obtained from artichoke heart CWM with no enzyme addition. CWM: cell wall material. ${ }^{c}$ DM: Degree of methylation. Ratio between moles of methanol and moles of GalA (uronic acids) per $100 \mathrm{~g}$ of sample.
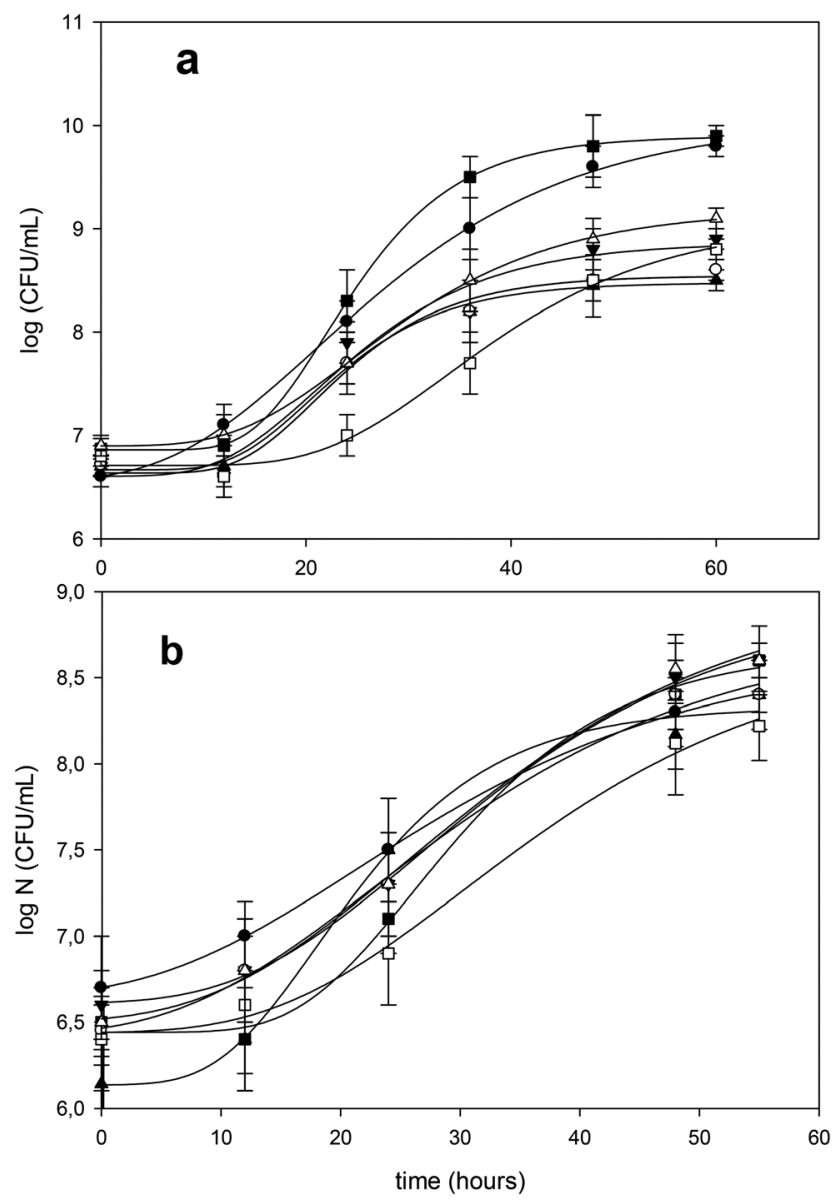

Fig. 2 Application of Gompertz model to experimental data of Lactobacillus plantarum 8114 (a) and Bifidobacterium bifidum (b) growth in different types of fibers: $\bullet$ MRS broth with glucose $(1 \%, w / v)$, MRS broth with fiber A $(1 \%, w / v), \Delta$ MRS broth with Fiber B $(1 \%, w / v), \nabla$ MRS broth with Fiber $C(1 \%, w / v), O$ MRS broth with Fiber D $(1 \%, w / v), \square$ MRS broth with Fiber $E(1 \%, w / v)$ and $\triangle$ MRS broth with Fiber $F(1 \%, w / v)$.

(Table 3). For B, C, D E and F fractions, the specific growth rate $(\mu)$ was similar to the one observed for glucose $\left(0.09 \mathrm{~h}^{-1}\right)$. The maximum population density (MPD) was similar for
Table 3 Gompertz parameters: specific growth rate $(\mu)$, maximum population density (MPD) and lag phase duration (LPD) for Lactobacillus plantarum 8114 and Bifidobacterium bifidum 11863 growth in MRS broth with glucose or different fractions isolated from artichoke ${ }^{a}$

\begin{tabular}{lccc}
\hline Substrate & $\mu\left(\mathrm{h}^{-1}\right)$ & LPD $(\mathrm{h})$ & $\begin{array}{l}\mathrm{MPD} \mathrm{Log} \\
(\mathrm{CFU} \mathrm{mL}\end{array}$ \\
\hline \multicolumn{2}{l}{ Lactobacillus plantarum 8114} & & \\
Glucose (MRS) & $0.09 \pm 0.009 \mathrm{~A}$ & $4.90 \pm 0.98 \mathrm{~A}$ & $10.11 \pm 0.26 \mathrm{~A}$ \\
Fraction A & $0.16 \pm 0.06 \mathrm{~B}$ & $14.75 \pm 0.36 \mathrm{BD}$ & $9.88 \pm 0.05 \mathrm{~B}$ \\
Fraction B & $0.09 \pm 0.02 \mathrm{~A}$ & $13.39 \pm 1.88 \mathrm{~B}$ & $8.47 \pm 0.18 \mathrm{C}$ \\
Fraction C & $0.09 \pm 0.04 \mathrm{~A}$ & $11.62 \pm 6.07 \mathrm{~B}$ & $8.86 \pm 1.67 \mathrm{BC}$ \\
Fraction D & $0.09 \pm 0.03 \mathrm{~A}$ & $13.53 \pm 3.42 \mathrm{~B}$ & $8.54 \pm 0.32 \mathrm{C}$ \\
Fraction E & $0.07 \pm 0.02 \mathrm{~A}$ & $21.62 \pm 4.39 \mathrm{CD}$ & $9.06 \pm 0.40 \mathrm{C}$ \\
Fraction F & $0.08 \pm 0.01 \mathrm{~A}$ & $13.27 \pm 0.45 \mathrm{~B}$ & $9.18 \pm 0.05 \mathrm{C}$ \\
Bifidobacterium bifidum 11863 & & \\
Glucose (MRS) & $0.04 \pm 0.001 \mathrm{~A}$ & $4.62 \pm 1.23 \mathrm{~A}$ & $8.65 \pm 0.10 \mathrm{~A}$ \\
Fraction A & $0.08 \pm 0.05 \mathrm{~A}$ & $16.10 \pm 4.25 \mathrm{BD}$ & $8.66 \pm 0.45 \mathrm{~A}$ \\
Fraction B & $0.09 \pm 0.03 \mathrm{~B}$ & $9.70 \pm 2.80 \mathrm{~B}$ & $8.32 \pm 0.33 \mathrm{~A}$ \\
Fraction C & $0.05 \pm 0.03 \mathrm{~A}$ & $13.54 \pm 3.01 \mathrm{~B}$ & $8.83 \pm 0.90 \mathrm{~A}$ \\
Fraction D & $0.05 \pm 0.02 \mathrm{~A}$ & $10.20 \pm 4.71 \mathrm{~B}$ & $8.63 \pm 0.44 \mathrm{~A}$ \\
Fraction E & $0.07 \pm 0.02 \mathrm{~A}$ & $21.16 \pm 2.71 \mathrm{CD}$ & $9.07 \pm 0.40 \mathrm{~A}$ \\
Fraction F & $0.05 \pm 0.03 \mathrm{~A}$ & $8.83 \pm 5.20 \mathrm{~B}$ & $9.02 \pm 0.78 \mathrm{~A}$
\end{tabular}

${ }^{a}$ Capital letters are used to describe differences in parameters in each column. Different letters correspond to significant differences between values.

glucose and fraction $\mathrm{A}$, and these were the higher values observed (9.88-10.11 $\left.\log \mathrm{CFU} \mathrm{mL}{ }^{-1}\right)$ while for other fractions the MPD values were in the range 8.47-9.18 $\log \mathrm{CFU} \mathrm{mL}^{-1}$. The lag phase duration (LPD) for the fractions ranged from 11.62 to $21.62 \mathrm{~h}$ and for glucose it took a significantly lower value of $4.90 \mathrm{~h}$.

In the case of Bifidobacterium bifidum 11863, the highest specific growth rate was obtained for fractions $\mathrm{A}$ and $\mathrm{B}$ $\left(0.08-0.09 \mathrm{~h}^{-1}\right)$, and this rate doubled the value observed for MRS broth with glucose $\left(0.04 \mathrm{~h}^{-1}\right)$, but differences were not significant for the growth on fraction A and glucose. The other fibers showed specific growth rates of $0.05-0.07 \mathrm{~h}^{-1}$, and differences between fibers were not statistically significant $(p>$ 0.05). MPD values ranged between 8.32 and $9.07 \log$ (CFU $\mathrm{mL}^{-1}$ ) for different fractions while for glucose, the MPD value 
was $8.65 \log \left(\mathrm{CFU} \mathrm{mL} \mathrm{m}^{-1}\right)$. The lag phase duration (LPD) showed significant variation for the different fractions ranging between 8.83 and $21.16 \mathrm{~h}$, and a value of $4.62 \mathrm{~h}$ was observed for glucose (Table 3).

Values obtained for specific growth rates are similar to those informed by Marotti et al. ${ }^{6}$ for Lactobacillus and Bifidobacterium on soluble fibers from modern, old durum and ancient type wheat varieties. Hernandez-Mendoza et al. ${ }^{20}$ reported higher specific growth rates and similar MPD for Lactobacillus reuteri and Bifidobacterium bifidum inoculated into a reconstituted whey containing sucrose and pectin in order to prepare a fermented probiotic product.

It can be concluded that L. plantarum 8114 showed a higher specific growth rate on fraction A than on glucose. Specific growth rate values were higher for this strain than for Bifidobacterium bifidum 11863 although differences were not statistically significant $(p>0.05)$.

\subsection{Growth of Lactobacillus plantarum 1814, Bifidobacterium bifidum 11863 and Escherichia coli 25922 on fractions enriched in soluble fiber}

One of the characteristic properties of a prebiotic substrate is that it should stimulate selectively the growth and/or activity of intestinal bacteria associated with health and wellbeing. Thus, the increase in population cell number was studied for strains of Lactobacillus and Bifidobacterium following $48 \mathrm{~h}$ growth on $1 \%(\mathrm{w} / \mathrm{v})$ glucose or on $1 \%(\mathrm{w} / \mathrm{v})$ fraction enriched in soluble fiber, and the same procedure was used to study the growth of E. coli 25922 which was chosen to represent the enteric portion of the commensal flora. The results are shown in Table 4.

For Lactobacillus strains, increase in cell density (CFU $\mathrm{mL}^{-1}$ ) on fractions $\mathrm{B}, \mathrm{C}, \mathrm{D}, \mathrm{E}$ and $\mathrm{F}$ was significantly lower (1.57-2.11) than cell density increase on glucose (3.00). The increases in cell density of L. plantarum 8114 for fiber A (2.94) and for glucose were similar. In the case of B. bifidum 11863, a significantly higher $(p<0.05)$ increase in cell density was observed when fibers A, B, C, D or F were present (1.90-2.03)

Table 4 Increase in cell density between time 0 and time $48 \mathrm{~h}$, reported as $\log$ (CFU $\mathrm{mL}^{-1}$ ) standard deviation, for bacterial cultures grown on glucose or on different fractions isolated from artichoke ${ }^{a}$

\begin{tabular}{llll}
\hline Substrate & $\begin{array}{l}\text { L. plantarum } \\
8114\end{array}$ & $\begin{array}{l}\text { Bifidobacterium } \\
\text { bifidum } 11863\end{array}$ & $\begin{array}{l}\text { E. coli } \\
25922\end{array}$ \\
\hline Glucose & $3.00 \pm 0.15 \mathrm{~A} \mathrm{a}$ & $1.60 \pm 0.10 \mathrm{~A} \mathrm{~b}$ & $1.47 \pm 0.06 \mathrm{~A} \mathrm{~b}$ \\
Fraction A & $2.94 \pm 0.19 \mathrm{~A} \mathrm{a}$ & $1.90 \pm 0.09 \mathrm{~B} \mathrm{~b}$ & $0.58 \pm 0.11 \mathrm{~B} \mathrm{c}$ \\
Fraction B & $1.57 \pm 0.20 \mathrm{~B} \mathrm{a}$ & $2.03 \pm 0.09 \mathrm{~B} \mathrm{~b}$ & $0.56 \pm 0.10 \mathrm{~B} \mathrm{c}$ \\
Fraction C & $2.11 \pm 0.13 \mathrm{~B} \mathrm{a}$ & $1.90 \pm 0.11 \mathrm{~B} \mathrm{a}$ & $0.57 \pm 0.10 \mathrm{~B} \mathrm{~b}$ \\
Fraction D & $1.84 \pm 0.21 \mathrm{~B} \mathrm{a}$ & $1.95 \pm 0.09 \mathrm{~B} \mathrm{a}$ & $0.60 \pm 0.08 \mathrm{~B} \mathrm{~b}$ \\
Fraction E & $1.70 \pm 0.23 \mathrm{~B} \mathrm{a}$ & $1.70 \pm 0.08 \mathrm{~A} \mathrm{a}$ & $0.59 \pm 0.09 \mathrm{~B} \mathrm{~b}$ \\
Fraction F & $2.00 \pm 0.11 \mathrm{~B} \mathrm{a}$ & $2.00 \pm 0.11 \mathrm{~B} \mathrm{a}$ & $0.62 \pm 0.09 \mathrm{~B} \mathrm{~b}$
\end{tabular}

${ }^{a}$ Capital letters are used to describe differences in cell density in each column. Lowercase letters are used to describe differences in cell density in each row. Different letters correspond to significant differences between values. than when glucose (1.60) was in the media. Growth of E. coli 25922 on all the fractions studied was significantly lower (0.56-0.62) than the growth on glucose (1.47), as can be observed in Table 4 .

\subsection{Prebiotic activity score}

Prebiotic activity scores for Lactobacillus plantarum 8114 and Bifidobacterium bifidum 11863 shown in Table 5 were derived from the cell density values of Table 4 through the use of eqn. (1). All scores calculated were positive. The higher the score, the higher the relative growth of the probiotic and/or the lower the relative growth of the $E$. coli, which indicates a higher and more selective use of prebiotics in relation to glucose by the probiotic microorganism and/or a limited use of prebiotic in relation to glucose by $E$. coli.

The highest prebiotic activity score was observed for Bifidobacterium bifidum grown in MRS broth and with fiber B added $(0.87)$ and the score for the other fibers were not significantly different $(p>0.05)$.

For Lactobacillus plantarum, the highest prebiotic score was observed for the microorganism grown on MRS broth with fiber A added (0.58). Lower scores were observed when L. plantarum was grown in the presence of fibers C, F, D, E and B $(0.31,0.24,0.19,0.16$ and 0.14 , respectively) although differences were not statistically significant $(p>0.05)$.

As can be observed in Table 5, there are significant differences $(p<0.05)$ in prebiotic activity scores between the two strains grown on fractions B, C, D, E and F, the values for Lactobacillus plantarum being lower than those for Bifidobacterium bifidum. This indicates that differences in their metabolic capacity apparently existed. The utilization of different fractions by the studied bacteria requires the presence of specific hydrolysis and transport systems and their presence or absence may be the cause for the different prebiotic scores observed. $^{14}$

The capacity of Lactobacilli and Bifidobacteria to utilize a diverse range of dietary carbohydrates has been previously informed and the literature links this capacity for metabolic adaptation to a complex carbohydrate-rich gastrointestinal

Table 5 Prebiotic activity scores of Lactobacillus plantarum 8114 and Bifidobacterium bifidum 11863 grown on different fractions isolated from artichoke ${ }^{a}$

\begin{tabular}{lll}
\hline Fraction & $\begin{array}{l}\text { Lactobacillus } \\
\text { plantarum } 8114\end{array}$ & $\begin{array}{l}\text { Bifidobacterium } \\
\text { bifidum11863 }\end{array}$ \\
\hline $\mathrm{A}$ & $0.58 \pm 0.21 \mathrm{~A} \mathrm{a}$ & $0.79 \pm 0.19 \mathrm{~A} \mathrm{a}$ \\
$\mathrm{B}$ & $0.14 \pm 0.18 \mathrm{~A} \mathrm{a}$ & $0.87 \pm 0.20 \mathrm{~A} \mathrm{~b}$ \\
$\mathrm{C}$ & $0.31 \pm 0.16 \mathrm{~A} \mathrm{a}$ & $0.80 \pm 0.23 \mathrm{~A} \mathrm{~b}$ \\
$\mathrm{D}$ & $0.19 \pm 0.16 \mathrm{~A} \mathrm{a}$ & $0.81 \pm 0.21 \mathrm{~A} \mathrm{~b}$ \\
$\mathrm{E}$ & $0.16 \pm 0.20 \mathrm{~A} \mathrm{a}$ & $0.67 \pm 0.19 \mathrm{~A} \mathrm{~b}$ \\
$\mathrm{~F}$ & $0.24 \pm 0.16 \mathrm{~A} \mathrm{a}$ & $0.86 \pm 0.21 \mathrm{~A} \mathrm{~b}$
\end{tabular}

${ }^{a}$ Capital letters are used to describe differences in prebiotic scores in each column. Lowercase letters are used to describe differences in prebiotic scores in each row. Different letters correspond to significant differences between values. 
tract environment. According to Pokusaeva et $a .^{21}$, for an average individual the human gastrointestinal tract (GIT) is a natural habitat for approximately $10^{11}-10^{12}$ microorganisms per gram of luminal content, collectively forming the gut microbiota with a total biomass of more than $1 \mathrm{~kg}$ in weight. The total number of bacterial species that may be contained within the intestinal microbiota ranges from approximately 500 to 1000 distinct bacterial species to between 15000 and 36000 different species. Lactobacilli and Bifidobacteria are among the prevalent groups thought to exert health-promoting actions in the GIT. Bifidobacteria can utilize a diverse range of dietary carbohydrates that escape degradation in the upper parts of the intestine, many of which are plant derived oligoand polysaccharides. Different bifidobacterial strains may possess different carbohydrate utilizing abilities. The gene content of a bifidobacterial genome reflects this apparent metabolic adaptation to a complex carbohydrate-rich gastrointestinal tract environment as it encodes a large number of carbohydrate-modifying enzymes, and this is a subject of actual study. The capacity of individual strains and species of Lactobacilli for carbohydrate metabolism differs substantially. This metabolic diversity conforms to the phylogenetic diversity in the genus Lactobacillus. Several species like L. acidophilus, L. casei, and L. plantarum metabolize a large diversity of different carbon sources, including all major categories of oligo- and polysaccharides. Oligosaccharides are preferentially metabolized by phosphotransferase/phospho-glycosyl hydrolase systems and oligosaccharide metabolism is repressed by glucose. Other species exhibit more restricted carbohydrate fermentation patterns, an extreme being the "nothing but maltose or sucrose" diet of several strains of $L$. sanfranciscensis. In this group of strains, oligosaccharides are preferentially metabolized by permease/phosphorylase systems and oligosaccharide metabolic enzymes are not repressed by glucose. ${ }^{22}$ Both groups are represented in intestinal habitats (e.g., L. acidophilus and L. reuteri) as well as food fermentations (e.g., L. plantarum and L. sanfranciscensis).Moreover, actual studies of carbohydrate consumption in model substrates and in food or intestinal ecosystems are trying to improve the understanding of these phenomena. ${ }^{22}$

Parkar et al. $^{23}$ reported gut health benefits exerted by kiwifruit pectins. Dongowski et $a .^{24}$ investigated the degradation, metabolism, fate, and selected effects of pectin in the intestinal tract of rats. They observed that total anaerobic and bacteroides counts were greater in groups fed with pectin and that they presented a higher concentration of short chain fatty acids (SCFA) in cecum and feces. During in vitro fermentation of pectin with fecal flora from rats, unsaturated oligogalacturonic acids appeared as intermediate products. With an increasing degree of methylation, the formation rate of SCFA decreased in the cecum of conventional rats. Low methoxyl pectins fermented faster than high methoxyl pectins in vivo and in vitro.

It has been reported that both inulin and oligofructose are effective prebiotics due to the stimulation of colonic bifidobacteria. Because of their recognized prebiotic properties, both are increasingly being used in new food product developments such as drinks, yoghurts, and biscuits. Bifidobacteria can inhibit gut pathogen growth, producing the fortification of the gut flora to resist acute infections. ${ }^{25-28}$

It can be concluded that fraction A presented the best performance concerning the growth of both strains. According to previously cited bibliography, the content of inulin and of pectin of a low degree of methylation might be the compositional reason for its selective stimulation of Lactobacillus plantarum 8114 and Bifidobacterium bifidum 11863 growth.

\section{Conclusions}

Dietary fiber fractions studied showed, in general, a potential capacity to selectively stimulate the growth of intestinal bacteria associated with health. Fractions isolated from artichoke stem with the use of heat pre-treatment and hemicellulase followed by ethanol precipitation (fraction A) had the highest prebiotic activity score for both strains since it was determined that:

- the highest specific growth rate of Lactobacillus plantarum 8114 was seen on this fraction with respect to glucose,

- a similar population density was achieved by Lactobacillus plantarum 8114 and Bifidobacterium bifidum 11863 when grown on this fraction and on glucose,

- a smaller increase in cell density was observed for Escherichia coli 25922 on this fraction with respect to glucose,

- a smaller increase in cell density was observed for Escherichia coli 25922 in comparison with that of Lactobacillus plantarum 8114 and Bifidobacterium bifidum 11863 when grown on this fraction.

This behavior might be attributed to the inulin and low methoxyl pectin contents of fraction A.

Other fractions also produced high prebiotic activity scores for Bifidobacterium bifidum 11863, but they showed lower prebiotic activity scores for Lactobacillus plantarum 8114.

The potential of fraction A to promote the growth of both tested strains in the gastrointestinal tract is promising. It is necessary to perform additional studies in order to evaluate the resistance of these fractions to different pHs and enzymes present in the human gastrointestinal tract and to analyze their gastrointestinal absorption and fermentation by the intestinal microflora where the competition for nutrients may influence bacterial survival, colonization and metabolic activity in the host.

\section{Acknowledgements}

This study was financially supported by University of Buenos Aires (UBACyT 20020100100726 and 20020130100550BA), National Agency of Scientific and Technical Research (PICT 38239 and 2012-1941) and CONICET (PIP 11220090100531 and 11220120100507). 


\section{References}

1 R. D. Berg, Trends Microbiol., 1996, 4, 430-435.

2 G. Gibson and M. Roberfroid, J. Nutr., 1995, 125, 14011412.

3 G. R. Gibson, H. M. Probert, J. Van Loo, R. A. Rastall and M. B. Roberfroid, Nutr. Res. Rev., 2004, 17, 259275.

4 M. Roberfroid, J. Nutr., 2007, 137, 830S-837S.

5 J. Leach, R. A. Rastall and G. R. Gibson, in Prebiotics: Development \& Application, ed. G. R. Gibson and R. A. Rastall, John Wiley \& Sons Ltd, Chichester, West Sussex, England, 2006, ch. 11, pp. 237-247.

6 I. Marotti, V. Bregola, I. Aloisio, D. Di Gioia, S. Bosi, R. Di Silvestro, R. Quinnand and G. Dinelli, J. Sci. Food Agric., 2012, 92(10), 2133-2140.

7 H. Kaplan and R. W. Hutkins, Appl. Environ. Microbiol., 2000, 66(6), 2682-2684.

8 J. Schrezenmeir and M. de Vrese, Am. J. Clin. Nutr., 2001, 73(2), 361S-364S.

9 E. Olano-Martin, G. R. Gibson and R. A. Rastall, J. Appl. Microbiol., 2002, 93, 505-511.

10 R. Palframan, G. R. Gibson and R. A. Rastall, Lett. Appl. Microbiol., 2003, 37, 281-284.

11 J. Vulevic, R. A. Rastall and G. R. Gibson, FEMS Microbiol. Lett., 2004, 236, 153-159.

12 G. Falony, K. Lazidou, A. Verschaeren, S. Weckx, D. Maes and L. De Vuyst, Appl. Environ. Microbiol., 2009, 75(2), 454461.

13 E. Fissore, C. Santo Domingo, C. A. Pujol, E. Damonte, A. M. Rojas and L. N. Gerschenson, Food Funct., 2014, 5(3), 463-470.
14 J. Huebner, R. L. Wehling and R. W. Hutkins, Int. Dairy J., 2007, 17, 770-775.

15 R. M. Atlas, in Handbook of microbiological media, ed. L. Park, CRC Press, Boca Raton, Florida, 1993, p. 673.

16 J. Huebner, R. L. Wehling, A. Parkhurst and R. W. Hutkins, Int. Dairy J., 2008, 18, 287-293.

17 M. H. Zwietering, F. M. Jongenburger, M. Roumbouts and K. vantRiet, Appl. Environ. Microbiol., 1990, 56, 1875-1881.

18 L. Giannuzzi, A. Pinotti and N. Zaritzky, Int. J. Food Microbiol., 1998, 39, 101-110.

19 M. J. Hopkins, J. H. Cummings and G. T. Macfarlane, J. Appl. Microbiol., 1998, 85, 381-386.

20 A. Hernandez-Mendoza, V. Robles, J. O. Angulo, J. De La Cruz and H. S. García, Food Technol. Biotech., 2007, 45(1), 27-31.

21 K. Pokusaeva, G. F. Fitzgerald and D. van Sinderen, Genes Nutr., 2011, 6(3), 285-306.

22 M. Gänzle and R. Follador, Front. Microbiol., 2012, 3, 340, DOI: $10.3389 /$ fmicb.2012.00340.

23 S. G. Parkar, E. Redagate, R. Wibisono, X. Luo, E. Koh and R. Schröder, J. Funct. Foods, 2010, 2(3), 210-218.

24 G. Dongowski, A. Lorenz and G. Proll, J. Nutr., 2002, 132(7), 1935-1944.

25 S. Kolida, K. Tuohy and G. R. Gibson, Br. J. Nutr., 2002, 87(2), 193-197.

26 M. Joossens, G. Huys, K. Van Steen, M. Cnockaert, S. Vermeire, P. Rutgeerts, K. Verbeke, P. Vandamme and V. De Preter, FEMS Microbiol. Ecol., 2011, 75(2), 343-349.

27 R. Pinheiro de Souza Oliveira, P. Perego, M. Nogueira de Oliveira and A. Converti, J. Food Eng., 2011, 107, 36-40.

28 E. Olano-Martin, G. R. Gibson and R. A. Rastall, J. Appl. Microbiol., 2002, 93, 505-511. 